\title{
Healthcare Utilization of Below Poverty Line Population under Government-Funded Health Protection Scheme in one sub- district in Bangladesh: A Cross-Sectional Study
}

Md. Zahid Hasan ( $\square$ md.zahid@icddrb.org )

icddr,b https://orcid.org/0000-0002-3824-8947

Mohammad Wahid Ahmed

icddr,b

Gazi Golam Mehdi

Health Systems and Population Studies Division, icddr,b

Jahangir AM Khan

Health Economics and Policy Unit, School of Public Health and Community Medicine, University of Gothenburg, Medicinaregatan 18A, 40530 Gothenburg, Sweden

Ziaul Islam

Health Systems and Population Studies Division, icddr,b

Mahbub Elahi Chowdhury

Health Systems and Population Studies Division, icddr

Sayem Ahmed

Liverpool School of Tropical Medicine

\section{Research Article}

Keywords: Health Protection Scheme, utilization of healthcare, below poverty line population, Bangladesh

Posted Date: January 4th, 2021

DOI: https://doi.org/10.21203/rs.3.rs-139778/v1

License: (c) (i) This work is licensed under a Creative Commons Attribution 4.0 International License. Read Full License 


\section{Abstract}

\section{Background}

The below poverty line (BPL) population in rural Bangladesh have low access to hospital inpatient-care (IPC) services. The Government of Bangladesh (GoB) launched pilot Shasthyo Suroksha Karmasuchi (SSK) at Kalihati Upazila of Tangail district in 2016 aiming to improve IPC access of the BPL population and financial protection for healthcare. The GoB funded scheme provides IPC for 78 diseases and outpatient consultation through an existing health facility. In this study, we aimed to assess the level of healthcare utilization among the scheme beneficiaries and identify the associated factors with utilization.

\section{Methods}

This was an exploratory study with a cross-sectional household survey conducted from July to September 2018 among 806 sampled households using a structured questionnaire. Data on illness and healthcare utilization was collected from the selected households for the last 90 days of the interview date. A logistic regression model was applied to determine the factors associated with healthcare utilization from SSK facility.

\section{Results}

Overall, $8 \%$ of the ill patients in the last 90 days prior to survey sought healthcare from SSK facilities ( $\mathrm{n}=639$; total patients who sought care), $28 \%$ from medically trained providers (MTPs), and 64\% from non-MTPs. Of the 23 (3.6\%) patients who sought inpatient care (IPC), less than half (10 patients) of them utilized IPC under SSK. Individuals with accident/injury, unemployed, having knowledge about SSK, non-BPL status, were more likely to utilize healthcare from SSK facility. Individuals reside more than $15 \mathrm{~km}$ away from facility, had 4-5 family members, and above secondary level education were less likely to utilize care from SSK facility.

\section{Conclusions}

It is evident that healthcare utilization of beneficiaries from the SSK scheme was very low. Effective strategies for enhancing knowledge on SSK benefits and precise BPL households targeting can be instrumental in increasing utilization of the scheme. The scheme also has a potential to bring the individuals under its coverage who utilize healthcare from other MTP and non-MTP.

\section{Background}

Universal health coverage (UHC) is now a familiar acronym for the global health agenda that combines a triple policy. It is defined as ensuring universal access to quality healthcare services as per need without the risk of incurring financial hardship [1]. More recently, the adaption of the sustainable development goals (SDGs) by the UN assembly explicitly included the UHC goal under SDG 3.8 stating "Achieve Universal Health Coverage, including financial risk protection, access to quality essential healthcare services, and access to safe, effective, quality, and affordable essential medicines and vaccines for all" [2]. Access to healthcare is considered as an important determinant in assessing equity in healthcare delivery [3]. Ideally, utilization of healthcare services reflects a need for care, however, that is not possible always for several reasons [4]. In low- and middle-income countries (LMICs), healthcare utilization is influenced not only by the demand side constraints but also by the supply side constraints. In some instances, such utilization is determined solely by the ability to pay or out-of-pocket (OOP) rather than the need for care [5]. This situation can gradually impose heavy financial burdens on individuals as well as households and in certain instances can lead to catastrophic healthcare expenditure (CHE) and economic impoverishment [6,7].

OOP spending is the major sources of healthcare payment in most of the LMICs including Bangladesh. The healthcare system of this country predominantly relies on OOP payment financing. It was estimated that, in 2015 , around $67 \%$ of the total healthcare expenditure was made as OOP [8]. Such high percentage of OOP expenditure for healthcare is associated with low financial protection of the households. Among 14 Asian countries, $15.6 \%$ of households faced CHE because of the high burden of OOP payments [9]. A recent study revealed that $14.7 \%$ of the household faces $\mathrm{CHE}$ from healthcare related OOP payments and $3.5 \%$ of the total population fall into poverty annually [10]. Another study conducted among 11 Asian countries showed that about 5 million people get impoverished annually in Bangladesh from OOP healthcare expenditure [11].

Page 2/18 
Public spending on health is determined by the capacity of the Government to raise revenues and allocate it to health sector [12]. Bangladesh still spends only $3 \%$ of its GDP in health sector while government expenditure in relation to GDP is only $0.69 \%$ placing Bangladesh at the least spending countries on health in South-East Asian Region [13]. The significantly increasing healthcare cost from the non-communicable disease burden and epidemiological transition (responsible for $60 \%$ of the mortality) have led to increase the OOP spending for healthcare. The National Health Policy of 2011 of the Government of Bangladesh (GOB) acknowledges that health is a human right and to achieve UHC, it is necessary to ensure healthcare services for the poor in an affordable cost [14]. For achieving UHC by 2030, effective measures have to be taken for reducing households' OOP healthcare related expenditure and increasing utilization of quality healthcare. Responding to the global call for UHC, the Government of Bangladesh adopted the first ever Health Care Financing Strategy (HCFS) in 2012 aiming to achieve UHC by 2032 [15]. Under the HCFS, the Shasthyo Surokhsha Karmasuchi (SSK), a health protection scheme of the GOB, is being piloted by the Health Economics Unit (HEU) of the Ministry of Health and Family Welfare (MoHFW) [16]. Although the SSK has a comprehensive plan to bring all the population of the country under the health insurance, initially aimed to pilot targeting the below poverty line (BPL) population only.

\section{Shasthyo Surokhsha Karmasuchi (SSK)}

This scheme is a model of health insurance that has started for piloting at Kalihati Upazila of Tangail District in 2016 and other two Upazilas - Modhupur and Ghatail of the same district in 2017. The scheme provides healthcare to the identified and enrolled BPL population. Upazila Health Complex (UpHC) is the first contact point of the beneficiaries. Enrolled households get inpatient care through UpHCs and on a structured referral basis from the Tangail District Hospital (TDH). Each household is provided with an electronic health card ensuring 50,000 BDT coverage per year for inpatient care of 78 different diseases against a government financed premium of 1,000 BDT per household per year. The key actors in the implementation of the SSK scheme were SSK cell, Scheme Operator (SO) and contracted hospitals. A detail description of the scheme is published elsewhere [17].

Health insurance scheme is viewed as an alternative to improve access to healthcare and reduce the direct financial burden in using care $[18,19]$. Though it is often predicted by the theory of health insurance, it does not always provide the expected financial protection for the "insured" people [20-22], since health is a multidimensional issue. A study found that insurance scheme increases healthcare utilization and reduces OOP payments among the beneficiaries [7]. The outpatient visits were favorable to the poor but the poorest had less access to inpatient care [23]. In India and Africa, Community Based Health Insurance (CBHI) had the positive effect on reducing the event of CHE [24-27]. On the other hand, subsidized health insurance scheme also worked for Columbia as it had positive effect on OOP payment reduction and health care utilization [28,29]. Askeskin program, a subsidized social health insurance in Indonesia had improved access to healthcare facilities and led an increase in outpatient utilization [30,31]. The evidence from Sokapheap Krousat Yeugn (SKY) micro-health insurance programme showed positive effect on utilization, reduced OOP health expenditure, but no effect on health status [32]. Another study conducted in Cambodia has shown that the integrated Social Health Protection Scheme (iSHPH) has enhanced HEF beneficiaries' utilization of public health services [33]. The evidence from Vajpayee Arogyashree scheme (VAS) suggests that it led to a substantial reduction in mortality driven by increased tertiary healthcare utilization. [34]. Focusing on Indian publicly financed health insurance schemes, an evidence prevails that the hospital services utilization increased after the introduction of these insurance schemes. Moreover, this increase in utilization has sustained over time and across regions [35].

Empirical evidence on the utilization of healthcare through SSK scheme is rare. Moreover, the Government is going to expand the scheme in some Upazilas initially and plan to implement across the country gradually. In this context, evidence on utilization of SSK scheme will help the key policymakers to develop more effective strategy for future implementation of the scheme. Thus, we aimed to assess the utilization of SSK scheme among the enrolled BPL population and identified the factors associated with the utilization.

\section{Material And Methods}

\section{Study design}

An exploratory study design with a cross sectional survey was used to examine the utilization of healthcare services through SSK scheme among insured BPL households. A community survey was conducted among the enrolled households of the scheme.

Page 3/18 


\section{Study setting}

The study was conducted in the Kalihati Upazila (sub-district) of Tangail District where the SSK is currently being piloted. The total households of this Upazila is 89,351 of which 35,740 (40\%) BPL households were enrolled in the SSK scheme. We included only Kalihati subdistricts for this study as the scheme here was comparatively matured than other two intended sub-districts i.e. Ghatail and Modhupur.

\section{Data collection}

A cross-sectional community survey was conducted using a standard pretested questionnaire. Information on socio-demographic characteristics of the households, illness and treatment related information of the members, and knowledge about the SSK scheme were collected. A six-member team of trained and experienced field research assistant ( 5 data collectors and a supervisor) interviewed the respondents from the selected households. Informed written consent was obtained before their participation in the survey. The survey was conducted between July to September 2018.

\section{Sampling}

The sample of the community survey was determined based on the utilization of such health protection scheme among the BPL population. A study showed that overall $19 \%$ of the insured population utilized healthcare from a health protection scheme called Rashtriya Swasthya Bima Yojana (RSBY) in India [36]. Based on this utilization rate, considering 95\% confidence interval and 3\% error level, a minimum of 657 households were required to interview for this study. Assuming $5 \%$ non-response rate and 1.2 design effect for clustering, total 828 households were selected for the interview.

A two-stage cluster sampling method was adopted two select the sampled households in the selected Upazila.. The SSK household list maintained by the Scheme Operator was used as sampling frame. There are 15 unions (collection of villages), in Kalihati Upazila. In the first phase, the unions were classified into three subgroups i.e. nearer, medium, and far using the distance of the unions to the Kalihati UpHC. Information on the distance was collected from the SSK Scheme Operator before the sampling. As the number of enrolled SSK households were not equal in each union, the estimated total sample was proportionately allocated for a union based on the total SSK enrolled households of the union. In the second phase, simple random sampling technique was used to select the SSK households from the lists of SSK households in each union. However, while visiting the sampled SSK households, we found that some of the SSK households didn't receive SSK cards yet and were not eligible to receive health care under the scheme. In such cases, instead of interviewing the listed households, we interviewed the adjacent households who had SSK card.

\section{Analysis}

Descriptive statistics of the household members and statistical inference test has been performed. In the descriptive statistics, the characteristics of the study participants were presented regarding frequency (n) and percentages (\%) with $95 \%$ confidence interval (CI). Utilization of healthcare has been presented by several dimensions e.g. sources of care, types of illness suffered (inpatient was defined as who required admission and stayed in the hospital overnight, and outpatient was defined as who didn't require admission to the hospital or require admission but didn't stay overnight), and types of care utilized. Beyond the utilization of SSK scheme we classified other two sources of healthcare utilization, firstly, medically trained providers (MTP) which includes care from medical college hospital, UpHCs, general practitioner, non-government organization (NGO) hospital, qualified private practitioner, Union Sub-Centre (USC), Maternal and Child Welfare Centre (MCWC) and secondly medically non-trained provider that includes unqualified private practitioner, traditional healer, drug sellers, and other unqualified sources.

A multiple logistic regression model was used to predict the likelihood of healthcare utilization from the SSK facility while controlling for demographic and household socioeconomic characteristics. The model is specified as:

$$
\operatorname{logit}\left(Y_{i}\right)=\beta_{1} X_{1 i}+\beta_{2} X_{2 i}+u_{i}
$$


Where, $Y_{i}=$ utilization status from SSK ( $1=y e s, 0=$ No), $X_{1} X_{2} \ldots$ are determining characteristics of healthcare utilization, $\beta_{1}, \beta_{2}, \ldots$ represents the coefficients of association and $\mathrm{u}_{\mathrm{i}}$ of the model.

\section{Results}

\section{Socio-demographic Characteristics}

Among the selected 828 households, finally 806 were interviewed in this study (97\% response rate). These households consisted of 3,178 members, mostly adults (58.4\%) followed by children (35.6\%), and elderly (6.1\%) (Table-1). The proportion of male to female was almost equal. More than half of these members were married. The majority of the members (47\%) had no education, while $27.5 \%$ of had primary, and $25.5 \%$ had secondary or above education level. About $27 \%$ of the household members were housewives and around $15 \%$ were agricultural workers or day labors. Most of the households (58.6\%) had 4-5 members, followed by less than 4 members (24.9\%), and more than six members (16.5\%). Around $36 \%$ individuals lived $15+\mathrm{km}$ away from the SSK facility while around $20 \%$ individuals stayed closer to the SSK facilities (less than $5 \mathrm{~km}$ ). More than one third of members belonged to the households having less than 10,250BDT (122 USD) income per month.

As per BPL household selection criterion, we found $66 \%$ of the SSK households were remained BPL at the time of interview. Regarding the knowledge of insurance scheme, about $68 \%$ of the visited SSK households knew about the SSK scheme. A higher proportion of beneficiaries (63\%) knew about the service provision of SSK scheme, however, their knowledge about the benefit package of SSK scheme was found to be low. The majority (56\%) of the beneficiaries reported of knowing about SSK scheme from the SSK representatives, followed by $25 \%$ from familiar people in locality, and $17 \%$ from relatives.

\section{Utilization of healthcare}

In the last 90 days recall period, almost $25 \%(n=781)$ of the surveyed individuals had self-reported illness or symptoms. Among the ill individuals, $81.8 \%(n=639)$ sought healthcare for their illness or symptoms from any types of healthcare providers. Only $8 \%$ of these individuals went to SSK facility for seeking healthcare. A large percentage (63.8\%) of them went to 'non-medically trained provider'. The majority of the individuals utilized healthcare from pharmacy (45.9\%), followed by public providers (20.7\%), and private providers (18.9\%). Of the total ill individuals, 3.6\% $(n=23)$ utilized inpatient care (IPC) from any sources and only 10 of 23 (43.5\% who required IPC) utilized IPC from SSK healthcare facility within 90 days prior to the survey.

While examining the utilization of SSK facilities by the background characteristics of the individuals, we found that the elderly (10.4\%), male (7.2\%), unemployed (12.1\%), having primary level education (9.1\%), having more than 6 members in the households (9.1\%), had accident or injury (17.2\%), and income level lower than 10,250 BDT (15.3\%) and lived in $5 \mathrm{~km}$ or less distance from SSK facility (17.9\%) had comparatively higher utilization from SSK facility compared to other corresponding groups. .

\section{Healthcare seeking behavior}

We found that, majority of the people utilized healthcare from the drug sellers (pharmacies) (45.9\%). Among the respondents utilized healthcare from medically trained provider, $12.5 \%$ of them went to private/NGO hospitals followed by scheme facility (SSK UpHC), and general practitioner (7.5\%), Medical college/specialized hospitals (5.5\%), and other qualified providers (USC/MCWC) $(2.7 \%)$.

While comparing the utilization by types of provider and types of reported illness, we found that $19.2 \%$ individual utilized SSK facility for accident/injuries while 34.6\% from other MTP and 46.2\% from non-MTPs.. Utilization from other MTP was the highest individuals who required female reproductive health and delivery services (76.5\%) and had non-communicable diseases (47.2\%). Utilization of non-MTP was the highest for communicable disease (66\%), Accident and injury (46\%) and for other illness (57\%).

\section{Associated factors of healthcare utilization from SSK facility}

Table 4The utilization of health care from SSK facility were significantly associated with occupation, education, types of selfreported illnesses, knowledge of SSK scheme, living distance of health facility, and current BPL status of the household. We found that unemployed are about four times (OR: $4.175 ; 95 \%$ Cl 1.01 - 17.24) more likely to utilize services from SSK facility compared to 
the agricultural/labor. Individuals having secondary or higher level of education were less likely to utilize healthcare from the SSK facility. Patients with accident and injury were almost five times more likely (OR: 5.11; 95\% Cl: $1.26-20.78)$ to utilize healthcare from SSK facilities than patients suffered from non-communicable disease. Member of households with 4-5 members were less likely to utilize healthcare from SSK facility compared to the households with less than 4 members. Individual who heard about SSK scheme were more likely to utilize healthcare from the SSK facility (OR: 10.61; 95\% Cl: 2.39 - 47.06). We observed that nonBPL household were above two times more likely to utilize healthcare from the SSK facility. Household distance of $15 \mathrm{~km}$ from the SSK facility were less likely to utilize healthcare from the scheme. We found that individuals from second income quintile were significantly utilized healthcare from the SSK facility compared to the poorest income quintile.

\section{Associated factor of healthcare utilization from any medically trained provider (MTP)}

Considering healthcare utilization status from any MTP (including SSK facility) as dependent variable, we found that having secondary and above level education were significantly associated with the MTP utilization compared to the no-institutional group. Similarly, people with self-reported injury and female reproductive problem utilized healthcare more compared to the people who suffered from non-communicable disease. Household size, knowledge of SSK scheme, BPL status and distance of nearest healthcare facility, and income quintiles didn't have any association with the utilization of MTPs.

\section{Discussion}

Overall, $8 \%$ of the cardholders who sought care for illness in the last 3 months visited SSK facilities and of the 23 cardholders who sought IPC, less than half (10 of 23 patients) of them sought IPC under SSK. The results of this study revealed that although the SSK health protection scheme provides free inpatients care and outpatient consultation services without fee and regular medicines, it is yet to be popular among the enrolled BPL households. A study conducted in India showed that such scheme significantly increased the utilization of inpatient healthcare among the beneficiaries [37].. Most of the enrolled people usually had symptoms and majority of them took healthcare services from pharmacies $(46 \%)$.. This segment of individuals who require outpatient cares can be attracted under the scheme through introducing outpatient benefit package. Evidence showed that involvement in insurance scheme resulted in increased utilization of outpatient care at public facilities [38].

One of the key reasons for such low utilization of the SSK scheme was the lack of knowledge about the scheme among the enrolled households. We found households' knowledge was significantly associated with the utilization of healthcare by the members from the scheme facility. Studies showed that knowledge of insurance scheme significantly affect the utilization of healthcare and dropout rates $[39,40]$. Although, the SSK management has developed an information, education, and communication (IEC) strategy, majority of the households didn't have knowledge on SSK scheme during the survey. This IEC strategy should be properly implemented among the target population. Moreover, community campaigns need to be strengthened to increase the demand for healthcare under this scheme. Households' distance from health facility also influenced the utilization of healthcare from the scheme. It is evident in literatures that spatial distribution significantly affect the utilization of healthcare from health facilities [41-43]. Even it is true for such health protection scheme that provides' free inpatient healthcare through the existing health facility. We observed that individuals from the currently non-BPL households were more likely to utilize healthcare from the SSK scheme. These individuals may reside near the scheme facility and may be better informed about the SSK services. It was evident that the individuals who belonged to the second income quintile were more likely to utilize healthcare from the SSK scheme compared to the poorest income group. The stylized fact is that utilization of healthcare is the lowest among the least well off group [44].

We found that unemployed individuals were more likely to utilize healthcare services from SSK facilities. The target population were poor; thus, the wage earner may have the higher opportunity costs of visiting to the healthcare facilities compared to the unemployed. Utilization of the scheme facility was significantly higher among the individuals suffered from accident/injury compared to the individuals suffered from communicable diseases. Similar finding was observed for a study conducted in a community-based health insurance scheme in Bangladesh [45].

The SSK scheme has a potential to increase the utilization among the enrolled BPL households by addressing the identified factors namely increasing knowledge through rigorous community campaign [46] and adding benefits for the out-patients under the scheme rather than only providing the free consultation services [47]. However, such mechanism needs to be examined in 
terms of sustainability and moral hazard. Further, list of BPL households should be updated at regular intervals for precise targeting and providing services to them who cannot afford it. Such precision may be possible by increasing local level political commitment. As the utilization of care was significantly negatively associated with the distance of healthcare SSK facility , the authority can probably think of linking the lower level facilities such as union sub-centre where the patient will get outpatient care and be referred to UpHC for inpatient services. However, further exploration would be required for such initiative. A comprehensive evaluation of this scheme including all three upazilas for examining the effect of the scheme in increasing healthcare utilization in comparison to the people from similar socio-economic group would be useful.

\title{
Limitations
}

One possible shortcoming of this study is that although the sample household was selected using simple random sampling technique, due to the real scenario at filed we found the sampled households were not eligible to get SSK services due to not having SSK cards, we interviewed the adjacent households instead of the selected households. Interview of such adjacent household may create selection bias. However, we used 3\% margin of error level to capture more households to reduce such bias. This was the first study that examined the healthcare utilization pattern and associated factors among the SSK BPL households in Bangladesh. Another limitation of this study was that the seasonal variation in utilization of healthcare has not been captured as the survey carried out from July to September 2018 which restricts us to establish the causality in vigorous way. Although we used the distance variable in the regression model, some other important variables (e.g. travel time and cost) were not considered as these may vary according to the road types and transportation facility. There was a possibility of recall bias as health service utilization data was collected using a self-reported questionnaire. Earlier studies used recall periods of 1 to 12 months for collecting similar data [48-50]. We used a 90 days recall period to reduce the possibility of recall bias.

\section{Conclusion}

This study investigated the level of healthcare utilization of the financially disadvantaged BPL population from the Government funded health protection scheme in Bangladesh. Utilization of healthcare from the scheme facility is low despite the provision of free IPC for 78 different types of diseases and outpatient consultation. Here, inadequate knowledge on scheme is one of the key barriers to utilization which might increase over time with appropriate measures e.g., developing and implementing interpersonal communication strategy, and organizing regular awareness building campaign. Further, as large number of people utilized care from non-qualified and other MTPs, the policymakers can think of redesigning the benefit package based on needs of the BPL population and motivate them to seek care from SSK facility. The evidence generated from this study will be useful to address the reasons behind low rate of scheme utilization and challenges to increase the effectiveness of SSK in terms of healthcare utilization among the target vulnerable group. Addressing the drawback associated with the healthcare utilization is important before further expansion or scale of the scheme. A successful scale of this scheme will be a vehicle to achieve UHC through addressing the need of healthcare for the people who cannot afford quality healthcare in Bangladesh.

\section{List Of Abbreviations}

\author{
BPL Below Poverty Line \\ $\mathrm{CBH} \quad$ Community Based Health Insurance \\ CHE Catastrophic Healthcare Expenditure \\ $\mathrm{Cl} \quad$ Confidence Interval \\ GoB Government of Bangladesh \\ HCFS Health Care Financing Strategy \\ HEU Health Economics Unit \\ IEC Information, Education, And Communication
}




\begin{tabular}{|c|c|}
\hline IPC & Inpatient-Care \\
\hline iSHPH & Integrated Social Health Protection Scheme \\
\hline LMICs & Low- and Middle-Income Countries \\
\hline MCWC & Maternal and Child Welfare Centre \\
\hline MoHFW & Ministry of Health and Family Welfare \\
\hline MTPs & Medically Trained Providers \\
\hline NGO & Non-Government Organization \\
\hline O०P & Out-Of-Pocket \\
\hline RSBY & Rashtriya Swasthya Bima Yojana \\
\hline SDGs & Sustainable Development Goals \\
\hline SKY & Sokapheap Krousat Yeugn \\
\hline so & Scheme Operator \\
\hline SSK & Shasthyo Suroksha Karmasuchi \\
\hline TDH & Tangail District Hospital \\
\hline UHC & Universal Health Coverage \\
\hline UN & United Nation \\
\hline UpHC & Upazila Health Complex \\
\hline USC & Union Sub-Centre \\
\hline VAS & Vajpayee Arogyashree Scheme \\
\hline
\end{tabular}

\section{Declarations}

\section{Authors' contributions}

MZH, MWA, MEC, and SA contributed to conceptualize the research idea, study design, literature search, writing, revising, and finalizing the manuscript with the support from GGM, ZI and JAMK. All authors read, revised, and approved the final version of the manuscript.

\section{Ethics approval and consent to participate}

This study was approved by the Research Review Committee and Ethical Review Committee of the icddr,b (Protocol\# PR-17047). All respondents of the study were interviewed after obtaining written informed consent and their participation was be voluntary.

\section{Consent for publication}

Not applicable

\section{Funding}


The study was funded by Swedish International Development Cooperation Agency -Sida (Grant \#: GR-01455). The funding body was not involved in the design of the study, collection, analysis, and interpretation of data, and writing of this manuscript.

\section{Acknowledgements}

icddr,b acknowledges with gratitude the commitment of Swedish International Development Cooperation Agency (Sida) to its research efforts and funding for this study. icddr,b is also thankful to the Governments of Bangladesh, Canada, Sweden, and the UK for providing core/unrestricted support. We are grateful to Dr. Mohd. Shahdat Hossain Mahmud (Director General, HEU), Dr. Md. Nurul Amin (Director Research, HEU), Dr. Mohammad Abul Bashar Sarker (Deputy Director, SSK Cell, HEU), Dr. Mohammad Rofiqul Islam (Deputy Director, SSK Cell, HEU) and Md. Azmal Kabir (Consultant, SSK Cell, HEU) for their co-operation in this study. We are also grateful to Mr. Ashadul Islam (the then Director General, HEU), Md. Nuruzzaman (the then Director Research, HEU), and the Dr. Md. Aminul Hasan (the then Deputy Director, HEU) for their support to conduct this study.

\section{Competing interests}

Md. Zahid Hasan: Received funding from Sida to conduct this research.

Mohammad Wahid Ahmed: Received funding from Sida to conduct this research.

Gazi Golam Mehdi: Received funding from Sida to conduct this research.

Sayem Ahmed: Received funding from Sida to conduct this research.

Ziaul Islam: Received funding from Sida to conduct this research.

Jahangir AM Khan: None declared

\section{Availability of data and materials}

Data are available and can be provided upon request.

\section{References}

1. Rahman HZ. Realizing Universal Health Coverage; Bangladesh: Challenges and Opportunities. Dhaka: Power and Participation Research centre (PPRC); 2016.

2. Nations U. N1529189. Gen Assem 70 Sess. 2015;16301:1-35.

3. Wagstaff A, Paci P, van Doorslaer E. On the measurement of inequalities in health. Soc Sci Med. 1991;33:545-57.

4. National Academies of Sciences; Engineering; and Medicine. Health-Care Utilization as a Proxy in Disability Determination. Heal. Util. as a Proxy Disabil. Determ. 2018.

5. Ahmed AU, Hill RV, Smith LC, Wiesmann DM. The world's most deprived: Characteristics and causes of extreme poverty and hunger. world's Most deprived Charact. causes Extrem. poverty Hunger. 2007.

6. Wagstaff A, van Doorslaer E. Catastrophe and impoverishment in paying for health care: With applications to Vietnam 19931998. Health Econ. 2003;12:921-34.

7. Ataguba JEO. Reassessing catastrophic health-care payments with a Nigerian case study. Heal Econ Policy Law. 2012;7:30926.

8. MOHFW. Bangladesh National Health Accounts 1997 - 2015. Dhaka; 2017.

9. van Doorslaer E, O'Donnell O, Rannan-Eliya RP, Somanathan A, Adhikari SR, Garg CC, et al. Catastrophic payments for health care in Asia. Heal Econ. 2007;16:1159-84.

10. Khan JAM, Ahmed S, Evans TG. Catastrophic healthcare expenditure and poverty related to out-of-pocket payments for healthcare in Bangladesh-an estimation of financial risk protection of universal health coverage. Health Policy Plan [Internet]. 2017;1-9. Available from: https://academic.oup.com/heapol/article-lookup/doi/10.1093/heapol/czx048 
11. van Doorslaer E, O'Donnell O, Rannan-Eliya RP, Somanathan A, Adhikari SR, Garg CC, et al. Effect of payments for health care on poverty van Doorslaer, E., O’Donnell, O., Rannan-Eliya, R. P., Somanathan, A., Adhikari, S. R., Garg, C. C., ... Zhao, Y. (2006). Effect of payments for health care on poverty estimates in 11 countries in Asia: an analy. Lancet. 2006;368:1357-64.

12. WHO. Global Health Expenditure Database [Internet]. World Heal. Organ. 2017. Available from: http://apps.who.int/nha/database

13. WHO Bangladesh. World Health Organization, Bangladesh National Health Accounts, an overview on the public and private expenditures in health sector. 2017.

14. MoHFW. The National Health Policy 2011. Dhaka; 2011.

15. MoHFW. Expanding Social Protection for Health: Towards Universal Coverage Health Care. Dhaka; 2012.

16. Health Economics Unit. Shasthyo Surokhsha Karmasuchi (SSK): Concept Paper [Internet]. Dhaka; 2014. Available from: www.sskcell.gov.bd

17. Ahmed S, Hasan MZ, Ahmed MW, Dorin F, Sultana M, Islam Z, et al. Evaluating the implementation related challenges of Shasthyo Suroksha Karmasuchi (health protection scheme) of the government of Bangladesh: a study protocol. BMC Health Serv Res [Internet]. 2018;18:552. Available from: https://doi.org/10.1186/s12913-018-3337-x

18. Jowett M, Contoyannis P, Vinh ND. The impact of public voluntary health insurance on private health expenditures in Vietnam. Soc Sci Med. 2003;56:333-42.

19. Sepehri A, Sarma S, Simpson W. Does non-profit health insurance reduce financial burden? Evidence from the Vietnam living standards survey panel. Health Econ. 2006;15:603-16.

20. Lindelow M, Wagstaff A. Health Shocks in China: Are the Poor and Uninsured Less Protected? World Bank Policy Res Work Pap. 2005;1-25.

21. Ekman B. Catastrophic health payments and health insurance: Some counterintuitive evidence from one low-income country. Health Policy (New York). 2007;83:304-13.

22. Wagstaff A, Lindelow M, Jun G, Ling X, Juncheng Q. Extending health insurance to the rural population: An impact evaluation of China's new cooperative medical scheme. J Health Econ. 2009;28:1-19.

23. Zeng W, Lannes L, Mutasa R. Utilization of health care and burden of out-of-pocket health expenditure in Zimbabwe: Results from a national household survey. Heal Syst Reform. Taylor \& Francis; 2018;4:300-12.

24. Fink G, Robyn PJ, Sié A, Sauerborn R. Does health insurance improve health? Evidence from a randomized community-based insurance rollout in rural Burkina Faso. J Health Econ. Elsevier B.V.; 2013;32:1043-56.

25. Parmar D, Reinhold S, Souares A, Savadogo G, Sauerborn R. Does community-based health insurance protect household assets? Evidence from rural Africa. Health Serv Res. 2012;47:819-39.

26. Robyn PJ, Fink G, Sié A, Sauerborn R. Health insurance and health-seeking behavior: Evidence from a randomized communitybased insurance rollout in rural Burkina Faso. Soc Sci Med. Elsevier Ltd; 2012;75:595-603.

27. Sheth K. Evaluating health-seeking behaviour, utilization of care, and health risk: Evidence from a community based insurance model in India. Health Econ. 2013;66:246-67.

28. Camacho A, Conover E. Effects of subsidized health insurance on newborn health in a developing country. Econ Dev Cult Change. University of Chicago Press Chicago, IL; 2013;61:633-58.

29. Miller G, Pinto D, Vera-Hernández M. Risk protection, service use, and health outcomes under Colombia's health insurance program for the poor. Am Econ J Appl Econ. 2013;5:61-91.

30. Sparrow R, Suryahadi A, Widyanti W. Social health insurance for the poor: Targeting and impact of Indonesia's Askeskin programme. Soc Sci Med [Internet]. Elsevier Ltd; 2013;96:264-71. Available from:

http://dx.doi.org/10.1016/j.socscimed.2012.09.043

31. Aji B, De Allegri M, Souares A, Sauerborn R. The impact of health insurance programs on out-of-pocket expenditures in Indonesia: An increase or a decrease? Int J Environ Res Public Health. 2013;10:2995-3013.

32. Levine D, Polimeni R, Ramage I. Insuring health or insuring wealth? An experimental evaluation of health insurance in rural Cambodia. J Dev Econ. Elsevier B.V.; 2016;119:1-15.

Page $10 / 18$ 
33. Bart Jacobs, Ashish Bajracharya, Jyotirmoy Saha, Chhorvann Chhea, Ben Bellows AFA 2017. Making free public healthcare attractive: optimizing health equity funds in Cambodia. 2017;

34. Sood N, Wagner Z. Social health insurance for the poor: Lessons from a health insurance programme in Karnataka, India. BMJ Glob Heal. 2018;3:1-6.

35. Azam M. Does Social Health Insurance Reduce Financial Burden? Panel Data Evidence from India. World Dev. Elsevier Ltd; 2018;102:1-17.

36. Chengyi X, Zhongxin L, Zengqiang C, Zhuzhi Y. Dynamic spreading behavior of homogeneous and heterogeneous networks. Prog Nat Sci. Taylor \& Francis; 2007;17:358-65.

37. Philip NE, Kannan S, Sarma SP. Utilization of Comprehensive Health Insurance Scheme, Kerala. Asia Pacific J Public Heal [Internet]. 2016;28:77S-85S. Available from: http://journals.sagepub.com/doi/10.1177/1010539515602306

38. Mebratie AD, Sparrow R, Yilma Z, Abebaw D, Alemu G, Bedi AS. The impact of Ethiopia's pilot community based health insurance scheme on healthcare utilization and cost of care. Soc Sci Med. 2019;220:112-9.

39. Cofie P, De Allegri M, Kouyate B, Sauerborn R. Effects of information, education, and communication campaign on a community-based health insurance scheme in Burkina Faso. Glob Health Action. United States; 2013;6:20791.

40. Yusuf HO, Kanma-Okafor OJ, Ladi-Akinyemi TW, Eze UT, Egwuonwu CC, Osibogun AO. Health Insurance Knowledge, Attitude and the Uptake of Community-Based Health Insurance Scheme among Residents of a Suburb in Lagos, Nigeria. West Afr J Med. Nigeria; 2019;36:103-11.

41. Habibov N. What determines healthcare utilization and related out-of-pocket expenditures in Tajikistan? Lessons from a national survey. Int J Public Health. Switzerland; 2009;54:260-6.

42. Stock R. Distance and the utilization of health facilities in rural Nigeria. Soc Sci Med. England; 1983;17:563-70.

43. Awoyemi TT, Obayelu OA, Opaluwa HI. Effect of Distance on Utilization of Health Care Services in Rural Kogi State, Nigeria. J Hum Ecol [Internet]. Routledge; 2011;35:1-9. Available from: https://doi.org/10.1080/09709274.2011.11906385

44. O'Donnell O. Access to health care in developing countries: breaking down demand side barriers. Cad Saude Publica. Brazil; 2007;23:2820-34.

45. Ahmed S, Sarker AR, Sultana M, Chakrovorty S, Ahmed MW, Dorin F, et al. The impact of community-based health insurance on the utilization of medically trained healthcare providers among informal workers in Bangladesh. PLoS One. United States; 2018;13:e0200265.

46. Wakefield M, Loken B, Hornik RC. Use of mass media campaigns to change health behaviour Useofmassmediacampaignstochangehealthbehaviour.pdf. Lancet [Internet]. 2010;376:1261-71. Available from: http://cms.csom.umn.edu/marketinginstitute/research/documents/Useofmassmediacampaignstochangehealthbehaviour.pdf

47. He R, Miao Y, Zhang L, Yang J, Li Z, Li B. Effects of expanding outpatient benefit package on the rationality of medical service utilisation of patients with hypertension: A quasi-experimental trial in rural China. BMJ Open. 2019;9:1-8.

48. Lu C, Chin B, Li G, Murray CJL. Limitations of methods for measuring out-of-pocket and catastrophic private health expenditures. Bull World Health Organ. 2009;87:238-44.

49. Bose M, Dutta A. Inequity in hospitalization care: a study on utilization of healthcare services in West Bengal, India. Int J Heal policy Manag. 2015;4:29-38.

50. Ranson MK. The Impact of SEWA's Medical Insurance Fund on Hospital Utilization and Expenditure. 2016.

\section{Tables}


Table 1. Background characteristics of the study population

\begin{tabular}{|c|c|c|c|}
\hline Characteristics & $\mathbf{n}$ & $\%$ & 95\% CI \\
\hline \multicolumn{4}{|l|}{ Age group } \\
\hline Child (0-17) & 1,130 & 35.6 & $(33.9-37.2)$ \\
\hline Adults $(18-60)$ & 1,855 & 58.4 & $(56.6-60.1)$ \\
\hline Elderly $(60+)$ & 193 & 6.1 & $(5.3-7.0)$ \\
\hline \multicolumn{4}{|l|}{ Sex } \\
\hline Male & 1,595 & 50.2 & $(48.4-51.9)$ \\
\hline Female & 1,583 & 49.8 & $(48.1-51.6)$ \\
\hline \multicolumn{4}{|l|}{ Marital status } \\
\hline Married & 1,758 & 55.3 & $(53.6-57.0)$ \\
\hline Unmarried & 1,292 & 40.7 & $(39.0-42.4)$ \\
\hline Widowed/separated/destitute & 128 & 4.0 & $(3.4-4.8)$ \\
\hline \multicolumn{4}{|l|}{ Occupation } \\
\hline Agricultural/labor & 467 & 14.7 & $(13.5-16.0)$ \\
\hline Housewife & 863 & 27.2 & $(25.6-28.7)$ \\
\hline Small business & 180 & 5.7 & $(4.9-6.5)$ \\
\hline Transport worker & 115 & 3.6 & $(3.0-4.3)$ \\
\hline Unemployed & 168 & 5.3 & $(4.6-6.1)$ \\
\hline Student & 794 & 25.0 & $(23.5-26.5)$ \\
\hline Service worker & 188 & 5.9 & $(5.1-6.8)$ \\
\hline Disabled/ age $<5$ years & 403 & 12.7 & $(11.6-13.9)$ \\
\hline \multicolumn{4}{|l|}{ Education of household members } \\
\hline No education & 1497 & 47.1 & $(45.4-48.8)$ \\
\hline Up to Primary level & 870 & 27.5 & $(25.9-29.0)$ \\
\hline Secondary level and above & 811 & 25.5 & $(24.0-27.1)$ \\
\hline \multicolumn{4}{|l|}{ Household size } \\
\hline Less than 4 persons & 791 & 24.9 & $(23.4-26.4)$ \\
\hline $4-5$ persons & 1,861 & 58.6 & $(56.8-60.3)$ \\
\hline 6 persons or more & 526 & 16.5 & $(15.3-17.9)$ \\
\hline \multicolumn{4}{|c|}{ Distance of SSK facility from union of the individuals } \\
\hline Less than or equal to $5 \mathrm{~km}$ & 627 & 19.73 & $(18.4-21.2)$ \\
\hline 6 to $10 \mathrm{~km}$ & 766 & 24.1 & $(22.6-25.6)$ \\
\hline 11 to $15 \mathrm{~km}$ & 637 & 20.04 & $(18.7-21.5)$ \\
\hline More than $15 \mathrm{~km}$ & 1,148 & 36.12 & $(34.5-37.8)$ \\
\hline \multicolumn{4}{|l|}{ Household Income category* } \\
\hline$<=8000$ & 622 & 19.6 & $(18.2-21.0)$ \\
\hline$>8000$ to $<=10250$ & 583 & 18.3 & $(17.0-19.7)$ \\
\hline$<10250$ to $<=14000$ & 644 & 20.3 & $(18.9-21.7)$ \\
\hline$>14000$ to $<=18500$ & 681 & 21.4 & $(20.0-22.9)$ \\
\hline$>18500$ & 648 & 20.4 & $(19.0-21.8)$ \\
\hline
\end{tabular}

*1 USD =83.7 BDT; June 2018, Bangladesh Bank

Table 2: Households' current BPL status, knowledge, and sources of information about the SSK scheme. 


\begin{tabular}{lrrr}
\hline & $\mathbf{N}=\mathbf{8 0 6}$ & $\%$ & $\mathbf{9 5 \%} \mathbf{C I}$ \\
\hline Current BPL status & & & \\
$\quad$ BPL & 529 & 65.6 & $(62.3-68.8)$ \\
\hline non-BPL & 277 & 34.4 & $(31.2-37.7)$ \\
\hline Heard about SSK scheme & & & \\
$\quad$ No & 260 & 32.3 & $(29.1-35.6)$ \\
\hline Yes & 546 & 67.7 & $(64.4-70.9)$ \\
\hline Knowledge on SSK service provision & & & \\
\hline$\quad$ Through card & 508 & 63.0 & $(59.6-66.3)$ \\
\hline Don't know & 298 & 37.0 & $(33.7-40.4)$ \\
\hline Knowledge on treatment expenses at the SSK* & & & \\
$\quad$ Free outpatient ticket & 361 & 44.8 & $(41.4-48.2)$ \\
\hline Free medicine for IPC & 358 & 44.4 & $(41-47.9)$ \\
\hline Free diagnostic test for IPC & 154 & 19.1 & $(16.5-22)$ \\
\hline Free referral facility to district hospital & 76 & 9.4 & $(7.6-11.7)$ \\
\hline Free treatment at referral DH & 71 & 8.8 & $(7-11)$ \\
\hline Source of information* & & & \\
\hline$\quad$ Representative from SSK & 527 & 55.9 & $(92.6-96.4)$ \\
\hline Familiar people in locality & 232 & 24.6 & $(37.7-45.9)$ \\
\hline$\quad$ & & \\
\hline Relative & 160 & 17.0 & $(25.2-32.7)$ \\
\hline$\quad$ Local leader & 16 & 1.7 & $(1.8-4.7)$ \\
\hline Other sources (miking, poster, TV) & 8 & 0.9 & $(0.7-2.9)$ \\
\hline
\end{tabular}

* Multiple responses

Table-3: Pattern of healthcare utilization

\begin{tabular}{lrrr}
\hline Characteristics & $\mathbf{n}$ & $\mathbf{\%}$ & $\mathbf{9 5 \%}$ CI \\
\hline Suffered any illness or symptoms & 781 & 24.6 & $(23.1-26.1)$ \\
Yes & 2397 & 75.4 & $(73.9-76.9)$ \\
\hline No & 103 & 13.2 & $(11.0-15.8)$ \\
\hline Types of self-reported illness/symptoms & 164 & 21.0 & $(18.3-24.0)$ \\
\hline Communicable & 29 & 3.7 & $(2.6-5.3)$ \\
\hline Non-communicable & 22 & 2.8 & $(1.9-4.2)$ \\
\hline Accident/Injury & 432 & 55.3 & $(51.8-58.8)$ \\
\hline Female reproductive & 31 & 4.0 & $(2.8-5.6)$ \\
\hline Symptoms & & \\
\hline Others & 639 & 81.8 & $(78.9-84.4)$ \\
\hline Seek healthcare among those who suffered & 142 & 18.2 & $(15.6-21.1)$ \\
\hline Yes & & \\
\hline No & 51 & 8.0 & $(6.1-10.4)$ \\
\hline Seek healthcare from medically trained provider among those who sought healthcare & 180 & 28.2 & $(24.8-31.8)$ \\
\hline SSK facility & 408 & 63.8 & $(60.0-67.5)$ \\
\hline Other medically trained provider & & \\
\hline Non-medically trained provider & 132 & 20.7 & $(17.7-24.0)$ \\
\hline Healthcare provider utilized & 121 & 18.9 & $(16.1-22.2)$ \\
\hline Public & 5 & 0.8 & $(0.3-1.9)$ \\
\hline Private & 293 & 45.8 & $(42.0-49.7)$ \\
\hline NGO & 88 & 13.8 & $(11.3-16.7)$ \\
\hline Pharmacy & & \\
\hline Traditional/other & 23 & 3.6 & $(2.4-5.4)$ \\
\hline Inpatient care (IPC) utilized & 616 & 96.4 & $(94.6-97.6)$ \\
\hline Yes & & & \\
\hline No & 10 & 43.5 & $(24.0-65.2)$ \\
\hline Source of IPC utilization & 13 & 56.5 & $(34.8-76.0)$ \\
\hline SSK facility & & \\
\hline Other providers & &
\end{tabular}


Table 4. Utilization of healthcare from SSK and non-SSK sources by background characteristics

\begin{tabular}{|c|c|c|c|c|c|c|}
\hline \multirow{2}{*}{ Characteristics } & \multirow[b]{2}{*}{$\mathrm{n}=639$} & \multicolumn{2}{|c|}{ Utilized SSK facility } & \multicolumn{2}{|c|}{ Utilized other facility } & \multirow[b]{2}{*}{$p$-value } \\
\hline & & $\%$ & $95 \%$ CI & $\%$ & $95 \%$ CI & \\
\hline \multicolumn{7}{|l|}{ Age group } \\
\hline Child (0-17) & 200 & 7.0 & $(4.2-11.5)$ & 93.0 & $(88.5-95.8)$ & 0.332 \\
\hline Adults $(18-60)$ & 379 & 7.7 & $(5.4-10.8)$ & 92.3 & $(89.2-94.6)$ & \\
\hline Elderly $(60+)$ & 60 & 13.3 & $(6.8-24.6)$ & 86.7 & $(75.4-93.2)$ & \\
\hline \multicolumn{7}{|l|}{ Sex } \\
\hline Male & 304 & 8.6 & $(5.9-12.3)$ & 91.4 & $(87.7-94.1)$ & 0.493 \\
\hline Female & 335 & 7.5 & $(5.1-10.8)$ & 92.5 & $(89.2-94.9)$ & \\
\hline \multicolumn{7}{|l|}{ Marital status } \\
\hline Married & 339 & 8.8 & $(6.4-12.0)$ & 91.2 & $(88.0-93.6)$ & \\
\hline Unmarried & 212 & 6.6 & $(3.9-10.9)$ & 93.4 & $(89.1-96.1)$ & 0.906 \\
\hline Widowed/separated/destitute & 28 & 7.1 & $(1.7-25.0)$ & 92.9 & $(75.0-98.3)$ & \\
\hline \multicolumn{7}{|l|}{ Occupation } \\
\hline Agricultural/labour & 101 & 5.9 & $(2.7-12.7)$ & 94.1 & $(87.3-97.3)$ & \\
\hline Housewife & 210 & 7.1 & $(4.3-11.5)$ & 92.9 & $(88.5-95.7)$ & \\
\hline Small business & 41 & 7.3 & $(2.3-20.6)$ & 92.7 & $(79.4-97.7)$ & 0.162 \\
\hline Transport worker & 18 & 5.6 & $(0.7-32.0)$ & 94.4 & $(68.0-99.3)$ & \\
\hline Unemployed & 31 & 22.6 & $(11.0-40.7)$ & 77.4 & $(59.3-89.0)$ & \\
\hline Student & 96 & 4.2 & $(1.6-10.6)$ & 95.8 & $(89.4-98.4)$ & \\
\hline Service worker & 27 & 11.1 & $(3.5-29.9)$ & 88.9 & $(70.1-96.5)$ & \\
\hline Disabled/age $<5$ years & 115 & 10.4 & $(6.0-17.5)$ & 89.6 & $(82.5-94.0)$ & \\
\hline \multicolumn{7}{|l|}{ Education of household members } \\
\hline No education & 372 & 8.6 & $(6.1-11.9)$ & 91.4 & $(88.1-93.9)$ & 0.025 \\
\hline Primary level (years 1-5) & 157 & 10.8 & $(6.8-16.8)$ & 89.2 & $(83.2-93.2)$ & \\
\hline Secondary level and above & 110 & 1.8 & $(0.5-7.0)$ & 98.2 & $(93.0-99.5)$ & \\
\hline \multicolumn{7}{|l|}{ Household size } \\
\hline Less than 4 persons & 211 & 8.5 & $(5.4-13.2)$ & 91.5 & $(86.8-94.6)$ & \\
\hline $4-5$ persons & 348 & 6.9 & $(4.7-10.1)$ & 93.1 & $(89.9-95.3)$ & 0.495 \\
\hline 6 persons or more & 80 & 11.3 & $(5.9-20.3)$ & 88.8 & $(79.7-94.1)$ & \\
\hline \multicolumn{7}{|l|}{ Self-reported illness/symptoms } \\
\hline Communicable & 96 & 12.5 & $(7.2-20.8)$ & 87.5 & $(79.2-92.8)$ & \\
\hline Non-communicable & 89 & 7.9 & $(3.8-15.7)$ & 92.1 & $(84.3-96.2)$ & 0.025 \\
\hline Accident/Injury & 26 & 19.2 & $(8.1-39.2)$ & 80.8 & $(60.8-91.9)$ & \\
\hline Female reproductive & 17 & 11.8 & $(2.8-38.0)$ & 88.2 & $(62.0-97.2)$ & \\
\hline Symptoms & 388 & 5.9 & $(4.0-8.8)$ & 94.1 & $(91.2-96.0)$ & \\
\hline Others & 23 & 8.7 & $(2.1-29.6)$ & 91.3 & $(70.4-97.9)$ & \\
\hline \multicolumn{7}{|l|}{ Household has heard about SSK } \\
\hline No & 191 & 1.0 & $(0.3-4.1)$ & 99.0 & $(95.9-99.7)$ & 0.000 \\
\hline Yes & 448 & 10.9 & $(8.4-14.2)$ & 89.1 & $(85.8-91.6)$ & \\
\hline \multicolumn{7}{|l|}{ Households current BPL status } \\
\hline BPL & 412 & 10.1 & $(6.8-14.8)$ & 89.9 & $(85.2-93.2)$ & 0.106 \\
\hline non-BPL & 227 & 6.8 & $(4.7-9.7)$ & 93.2 & $(90.3-95.3)$ & \\
\hline \multicolumn{7}{|l|}{ Distance of SSK facility } \\
\hline Less than or equal to $5 \mathrm{~km}$ & 123 & 17.9 & $(12.0-25.7)$ & 82.1 & $(74.3-88.0)$ & \\
\hline 6 to $10 \mathrm{~km}$ & 156 & 10.9 & $(6.9-16.9)$ & 89.1 & $(83.1-93.1)$ & 0.000 \\
\hline 11 to $15 \mathrm{~km}$ & 125 & 3.2 & $(1.2-8.3)$ & 96.8 & $(91.7-98.8)$ & \\
\hline More than $15 \mathrm{~km}$ & 235 & 3.4 & $(1.7-6.7)$ & 96.6 & $(93.3-98.3)$ & \\
\hline \multicolumn{7}{|l|}{ Income categories in BDT } \\
\hline$<=8000$ & 113 & 3.5 & $(1.3-9.1)$ & 96.5 & $(90.9-98.7)$ & \\
\hline$>8000$ to $<=10250$ & 119 & 11.8 & $(7.1-18.9)$ & 88.2 & $(81.1-92.9)$ & 0.102 \\
\hline$<10250$ to $<=14000$ & 138 & 6.5 & $(3.4-12.1)$ & 93.5 & $(87.9-96.6)$ & \\
\hline$>14000$ to $<=18500$ & 124 & 9.7 & $(5.6-16.3)$ & 90.3 & $(83.7-94.4)$ & \\
\hline$>18500$ & 145 & 8.3 & $(4.7-14.0)$ & 91.7 & $(86.0-95.3)$ & \\
\hline
\end{tabular}

*1 USD =83. 7 BDT; June 2018, Bangladesh Bank 
Table 5. Factors associated with the utilization of healthcare from SSK facility 


\begin{tabular}{|c|c|c|}
\hline \multirow[t]{2}{*}{ Socio demographic factors } & \multirow{2}{*}{\multicolumn{2}{|c|}{ Healthcare utilization from SSK facility Healthcare utilization from MTF }} \\
\hline & OR $(95 \% \mathrm{CI})$ & \\
\hline \multicolumn{3}{|l|}{ Age group } \\
\hline Child (0-17) & 1 & 1 \\
\hline Adults $(18-60)$ & $1.323(0.15,11.29)$ & $0.981(0.35,2.78)$ \\
\hline Elderly $(60+)$ & $2.150(0.21,22.37)$ & $0.977(0.31,3.06)$ \\
\hline \multicolumn{3}{|l|}{ Sex } \\
\hline Male & 1 & 1 \\
\hline Female & $1.422(0.53,3.79$ & $1.012(0.62,1.66)$ \\
\hline \multicolumn{3}{|l|}{ Marital status } \\
\hline Married & 1 & 1 \\
\hline Unmarried & $0.581(0.08,4.29$ & $0.632(0.26,1.57)$ \\
\hline Widowed/separated/destitute & $0.265(0.04,1.77)$ & $0.833(0.36,1.91)$ \\
\hline \multicolumn{3}{|l|}{ Occupation } \\
\hline Agricultural worker/labor & 1 & 1 \\
\hline Housewife & $0.669(0.18,2.53$ & $1.932 * *(1.01,3.68)$ \\
\hline Small business & $0.880(0.18,4.27)$ & $1.188(0.54,2.62)$ \\
\hline Transport worker & $0.652(0.06,6.74)$ & $0.345(0.07,1.61)$ \\
\hline Unemployed & $4.175^{* *}(1.01,17.24)$ & $1.838(0.79,4.26)$ \\
\hline Student & $1.023(0.13,8.26)$ & $1.518(0.53,4.31)$ \\
\hline Service worker & $1.260(0.23,6.92)$ & $1.810(0.76,4.30)$ \\
\hline Disabled/age $<5$ years & $2.858(0.58,14.18)$ & $2.038(0.83,5.03)$ \\
\hline \multicolumn{3}{|l|}{ Education of household members } \\
\hline No institutional education & 1 & 1 \\
\hline Primary level (years 1-5) & $1.478(0.66,3.32)$ & $1.414(0.92,2.18)$ \\
\hline Secondary level and above & $0.215^{*}(0.04,1.03)$ & $1.565 *(0.96,2.56)$ \\
\hline \multicolumn{3}{|l|}{ Self-reported illness/symptoms } \\
\hline Non-communicable & $1(1.00,1.00)$ & $1(1.00,1.00)$ \\
\hline Communicable & $2.277(0.77,6.76)$ & $1.201(0.68,2.12)$ \\
\hline Accident/Injury & $5.112^{* *}(1.26,20.78)$ & $2.723 * *(1.16,6.38)$ \\
\hline Female reproductive problem & $2.910(0.46,18.44)$ & $3.717 * * *(1.37,10.08)$ \\
\hline Symptoms & $1.171(0.44,3.10)$ & $0.853(0.56,1.31)$ \\
\hline Others & $1.505(0.26,8.62)$ & $1.140(0.49,2.67)$ \\
\hline \multicolumn{3}{|l|}{ Household size } \\
\hline Less than 4 persons & 1 & 1 \\
\hline $4-5$ persons & $0.472^{* *}(0.22,1.00)$ & $1.008(0.70,1.46)$ \\
\hline 6 persons or more & $0.917(0.33,2.55)$ & $1.001(0.57,1.75)$ \\
\hline \multicolumn{3}{|l|}{ Heard about SSK } \\
\hline No & 1 & 1 \\
\hline Yes & $10.61 * * *(2.39,47.06)$ & $0.918(0.63,1.33)$ \\
\hline \multicolumn{3}{|l|}{ Current BPL status } \\
\hline BPL & 1 & 1 \\
\hline non-BPL & $2.443 * *(1.22,4.90)$ & $0.748(0.52,1.07)$ \\
\hline \multicolumn{3}{|c|}{ Distance of health facility from union } \\
\hline Less than or equal to $5 \mathrm{~km}$ & 1 & \\
\hline 6 to $10 \mathrm{~km}$ & $0.734(0.34,1.59)$ & $1.111(0.69,1.79)$ \\
\hline 11 to $15 \mathrm{~km}$ & $0.195^{* * *}(0.06,0.63)$ & $0.778(0.46,1.31)$ \\
\hline More than $15 \mathrm{~km}$ & $0.231 * * *(0.09,0.58)$ & $0.731(0.46,1.15)$ \\
\hline \multicolumn{3}{|l|}{ Income categories } \\
\hline$<=8000$ & 1 & 1 \\
\hline$>8000$ to $<=10250$ & $4.188^{* *}(1.18,14.91)$ & $1.069(0.61,1.89)$ \\
\hline$<10250$ to $<=14000$ & $1.531(0.41,5.68$ & $1.162(0.68,1.99)$ \\
\hline$>14000$ to $<=18500$ & $2.591(0.71,9.50)$ & $1.789 * *(1.03,3.10)$ \\
\hline$>18500$ & $1.990(0.55,7.15)$ & $1.190(0.69,2.06)$ \\
\hline \multicolumn{3}{|l|}{ Constant } \\
\hline $\mathrm{N}$ & 781.00 & 781 \\
\hline Loglikelihood & -145.90 & -444 \\
\hline Chi-square & 85.09 & 60.5 \\
\hline -value & 0.000 & 0.001 \\
\hline Pseudo- $\mathrm{R}^{2}$ & 0.226 & 0.064 \\
\hline
\end{tabular}

$* p<0.1 ; * * p<0.05 ; * * * p<0.01$ 


\section{Figures}

Figure 1: Utilization of health care by different providers

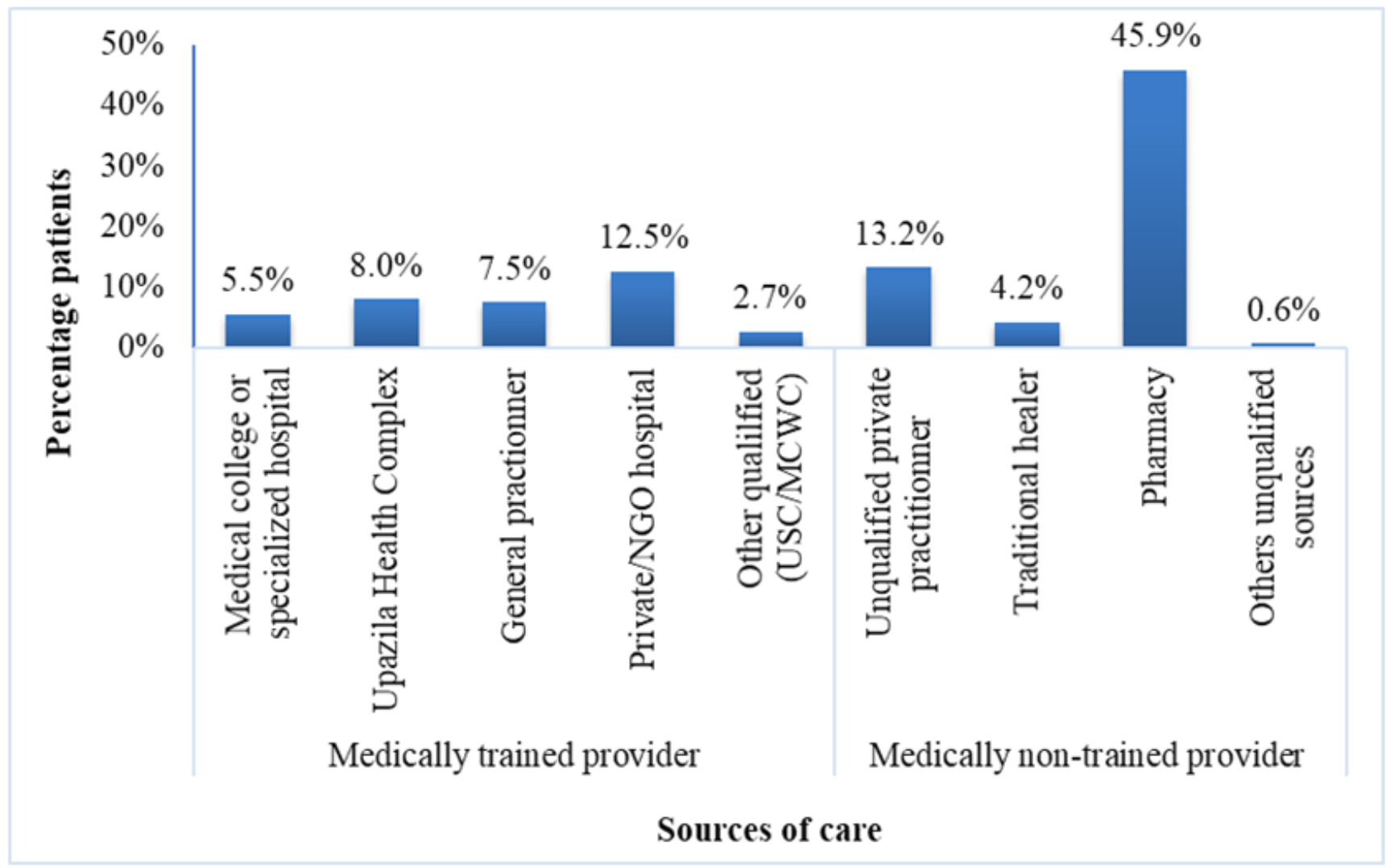

Figure 1

Utilization of health care by different providers 
Figure 2: Utilization of SSK, Medically and non-medically trained provider by type of illness

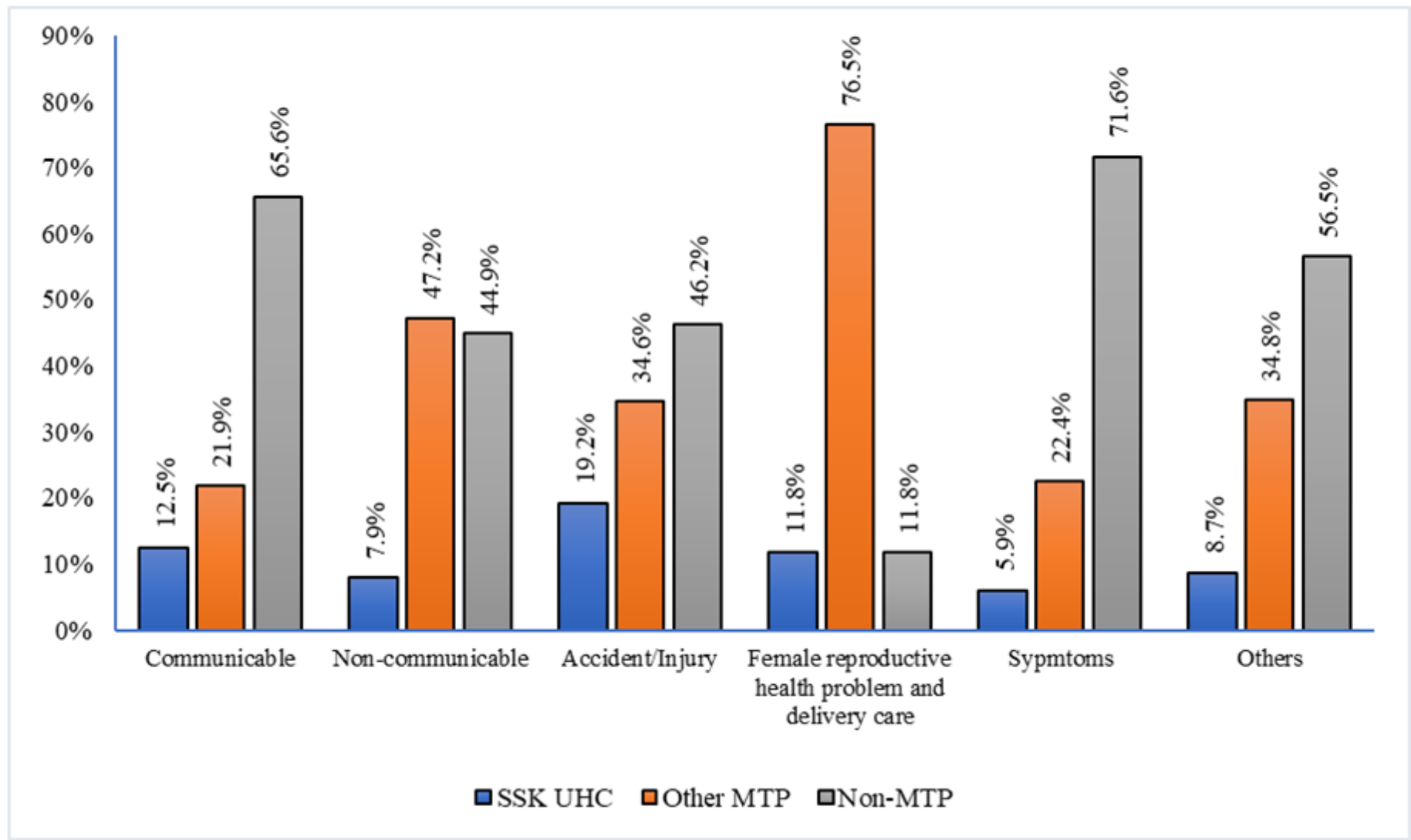

Figure 2

Utilization of SSK, Medically and non-medically trained provider by type of illness 